Article

\title{
Influence of the Depth on the Shape and Thickness of Nacre Tablets of Pinctada margaritifera Pearl Oyster, and on Oxygen Isotopic Composition
}

\section{Marthe Rousseau $^{1, *}$ and Claire Rollion-Bard ${ }^{2}$}

1 UMR7561 PPIA, Faculté de médecine, Biopôle, 9 Avenue de la forêt de Haye, BP 184, Vandoeuvre-lès-Nancy 54505, France

2 CRPG-CNRS, Université de Lorraine, BP 20, Vandoeuvre-lès-Nancy 54500, France; E-Mail: rollion@crpg.cnrs-nancy.fr

* Author to whom correspondence should be addressed; E-Mail: rousseam@gmx.net; Tel.: +00-33-383-685-434; Fax: +00-33-383-685-409.

Received: 1 February 2012; in revised form: 24 February 2012 / Accepted: 9 March 2012 / Published: 19 March 2012

\begin{abstract}
Nacre, or mother of pearl, is composed of aragonite tablets and is produced by some mollusks. Because of the highly organized internal structure, chemical complexity, mechanical properties and optical effects of nacre, its formation is among the best-studied examples of calcium carbonate biomineralization. The pearl oyster Pinctada margaritifera is harvested in French Polynesia for pearl farming. The quality of the pearl depends on the quality of the nacre on its surface and its iridescent colors are affected by the thickness of the layers. Here we report on an experimental study conducted to influence the shape and the thickness of nacre tablets by keeping pearl oysters at four different depths $(7,20,30$ and $39 \mathrm{~m}$ ) for one week. Scanning electron microscopy was used to measure the thickness of the nacre tablets and to analyze their final shape. The shape of the tablets changed from hexagonal to rhomboid at a depth of $39 \mathrm{~m}$. The change in shape led to a change in size. The thickness of the tablets was reduced by between 16 and $30 \%$ on average. We also measured the oxygen isotopic composition using Secondary Ion Mass Spectrometry. In this study, we demonstrated that depth can modify the size, shape and thickness of nacre tablets, but not the $\delta^{18} \mathrm{O}$. This environmental modification is important for the biomineralization of the shell of the pearl oyster Pinctada margaritifera.
\end{abstract}

Keywords: biomineralization; nacre; pearl oyster 


\section{Introduction}

Nacre, or mother of pearl, is a calcium carbonate structure produced by bivalves, gastropods, and cephalopods as an internal shell coating. The combination of the highly organized internal structure, chemical complexity, mechanical properties and optical effects of this biomineral are responsible for its characteristic beautiful luster.

Shells and pearls often have an iridescent color. The phenomenon has been attributed to both diffraction and interference. The shell of the mollusk Pinctada margaritifera has very strong iridescent colors, which depend on the thickness of the last few layers of nacre and the regularity of the tablets at the surface of the shell [1].

The metabolism and growth of mollusks are influenced by their environment which, in turn, influences the size and shape of the shell $[2,3]$. Wada reported changes in the shape and growth rate of nacre tablets over the course of the year as a function of the season and of the temperature of the water [4]. The same observation was made on Pinctada fucata, a species living in the Ago Bay in the Mie Prefecture of Japan, where the water temperature can vary by as much as 10 to $15^{\circ} \mathrm{C}$. In contrast, in French Polynesian lagoons, water temperature variations are not as large.

In this study, we tested if depth could change the shape of nacre tablets, the final objective being to modify the optical properties of nacre. We also checked if depth could have an influence on the oxygen isotopic composition of the shell, this composition being an important proxy in paleoclimatic reconstructions. Indeed, isotopic compositions in biocarbonates, and more particularly, oxygen isotopic compositions are used as proxy of temperature and sea level change. It is based on the relationship first described by Urey [5] linking the isotopic fractionation to the temperature. The first paleo-environmental reconstructions were done by Epstein et al. [6,7] based on an empirical relationship for mollusk shells. Since, it was shown that some "vital effects" [8] can superimposed to the relationship between temperature and oxygen isotopic compositions. So it was important to know if the depth could have a consequence on these vital effects, because it would add another parameter to know if we want to apply the oxygen isotopic composition as proxy of temperature.

Here we report on an experimental study in which we tried to influence the shape and the thickness of nacre tablets by keeping pearl oysters at four different depths $(7,20,29$ and $39 \mathrm{~m})$ for one week.

\section{Results and Discussion}

\subsection{Scanning Electron Microscopy Observations}

Scanning electron microscopy (SEM) was necessary for the observation of nacre tablets, which are only a few $\mu \mathrm{m}$ in circumference and around $500 \mathrm{~nm}$ thick. Our observations of the growing surface of the pearl oyster shell provided information about changes in the shape of the tablets. At a depth of $7 \mathrm{~m}$, nacre tablets were elongated hexagonals (Figure 1) in the first and second year. At a depth of $20 \mathrm{~m}$, the tablets were regular hexagonals (Figure 2). Figure 3 shows the elongation of the nacre tablets between a depth of $30 \mathrm{~m}$ (second year) and a depth of $39 \mathrm{~m}$ (first year) before the tablets became rhomboid. Figure 4 shows the different shapes of the nacre tablets as a function of depth. A change in the long axis in the growth direction was observed. Because of their shape, the growing tablets do not come into 
contact with each other as soon as for the other shape. The tablets can thus continue to grow and are finally bigger. This is related to the way tablets grow following a Voronoi process [9].

Figure 1. Scanning electron microscopy (SEM) images of nacre surface of pearl oyster kept at a depth of $7 \mathrm{~m}$ (First Year: A: ×1,000; B: ×8,000; Second Year: C: ×1,000; D: ×8,000).
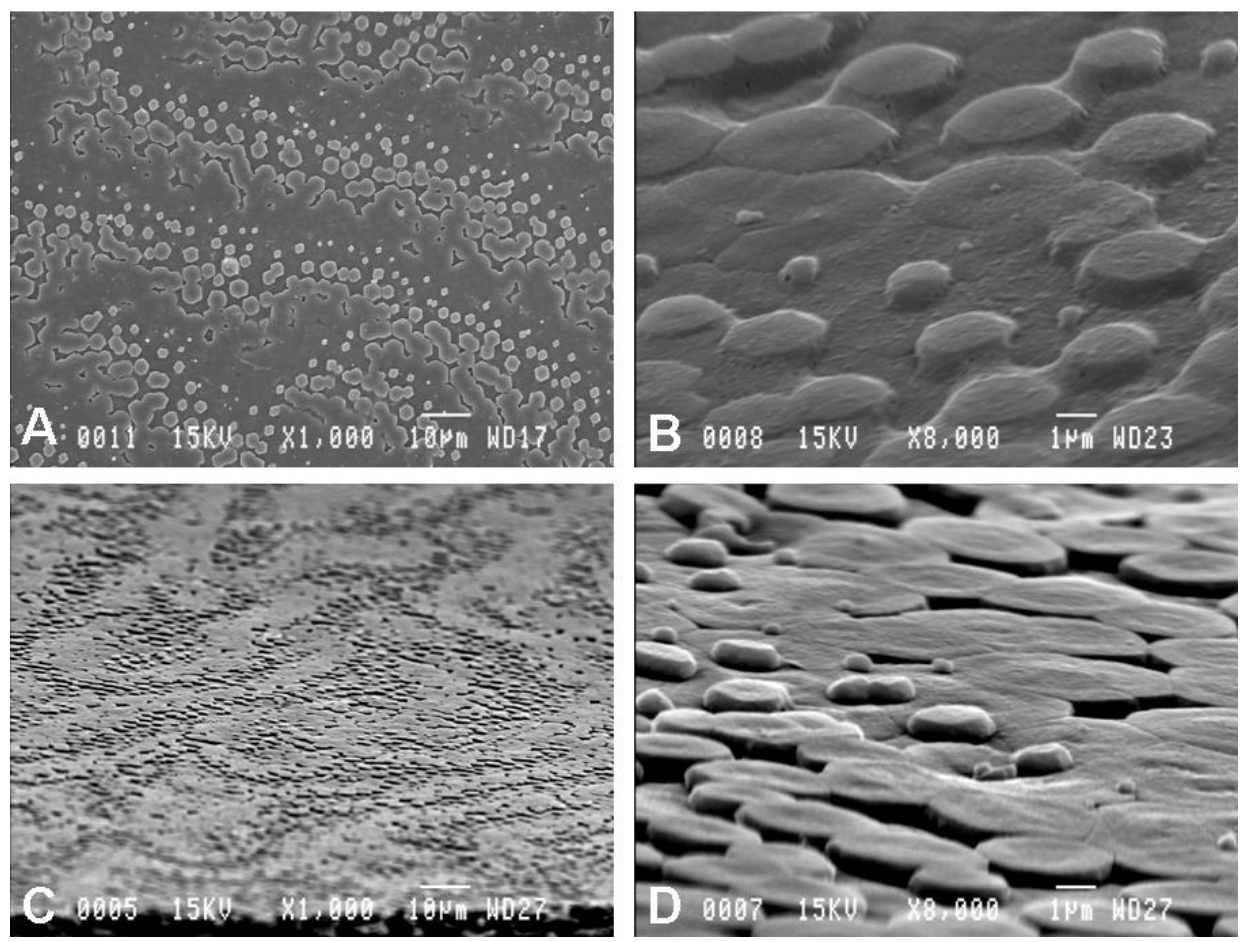

Figure 2. SEM images of nacre surface of pearl oyster kept at a depth of $20 \mathrm{~m}$ (First Year: A: $\times 1,000$; B: $\times 8,000$; Second Year: C: $\times 1,000 ; \mathrm{D}: \times 8,000)$.
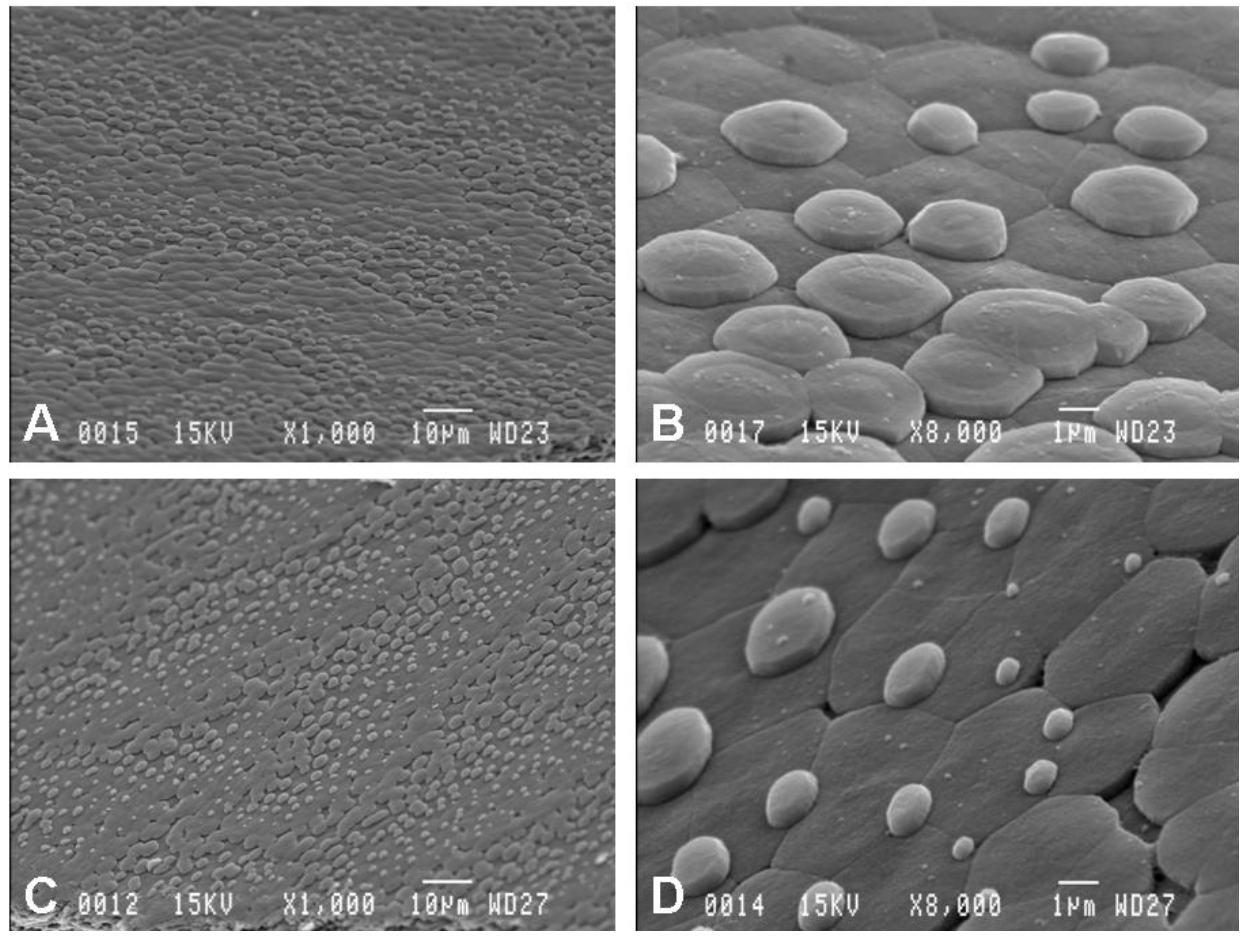
Figure 3. SEM images of nacre surface of pearl oyster kept at a depth of $30 \mathrm{~m}(\mathrm{~A}: \times 1,000$; $\mathrm{B}: \times 8,000)$ and of $39 \mathrm{~m}(\mathrm{C}: \times 1,000 ; \mathrm{D}: \times 8,000)$.
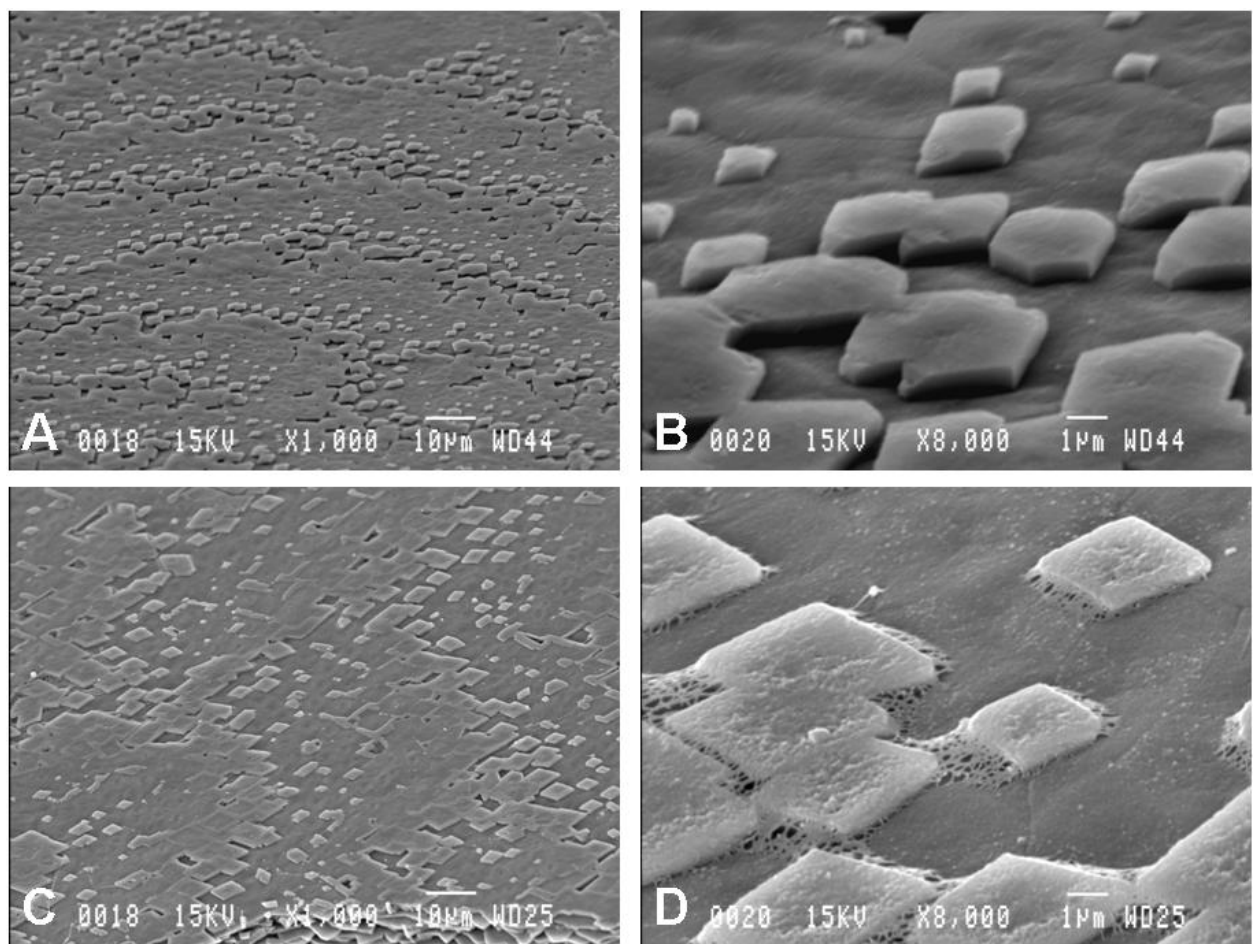

Figure 4. Shape of the nacre tablet as a function of depth, in relation to the shell growth direction.

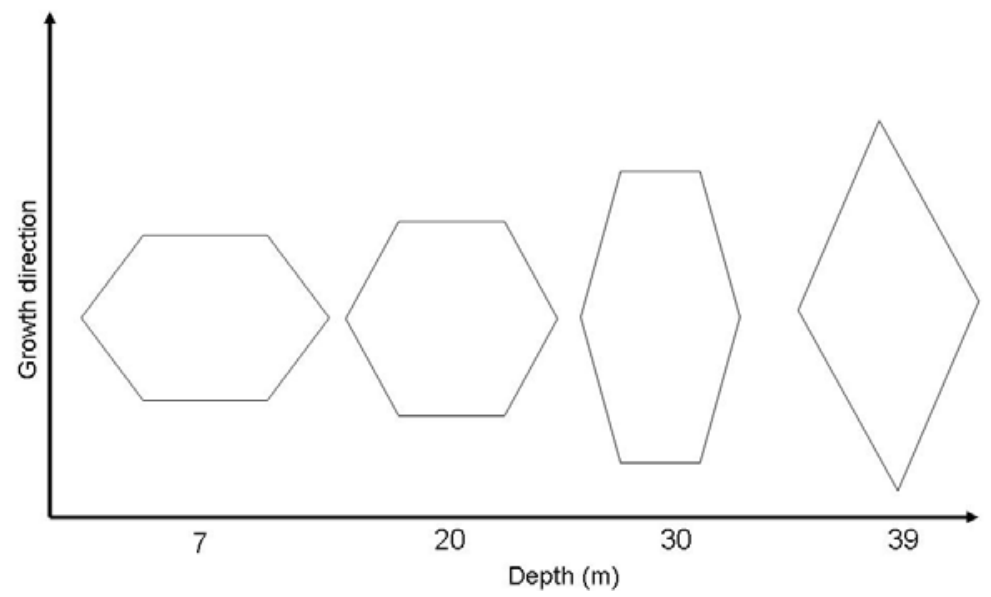

\subsection{Oxygen Isotope Measurements}

About 10 measurements of $\delta^{18} \mathrm{O}$ were performed in the aragonite part of the shell, in the inner nacreous layer to make sure that the shell had been deposited during the course of the experiment. $\delta^{18} \mathrm{O}$ values varied from -2.48 to $-0.94 \%$ (average $-1.86 \pm 0.50 \%, \mathrm{n}=10$ ) for the shell deposited at a depth of $39 \mathrm{~m}$, from -2.65 to $-0.83 \%$ o (av. $-1.70 \pm 0.67 \%$, $\mathrm{n}=13$ ) for a depth of $20 \mathrm{~m}$, from -2.96 to $-0.02 \%$ (av. $-1.59 \pm 0.96 \%, \mathrm{n}=12$ ) for a depth of $7 \mathrm{~m}$, and from -3.09 to $-1.09 \%$ (av. $-2.38 \pm 0.63 \%, \mathrm{n}=9$ ) for the control. 
The $\delta^{18} \mathrm{O}$ in carbonate is determined by the $\delta^{18} \mathrm{O}$ of the water and by the temperature at which the carbonate is deposited. In biogenic carbonates, there is also an additional effect called the "vital effect". This effect varies with the organism [10]. To our knowledge, to date there has been no study of the influence of depth on the $\delta^{18} \mathrm{O}$ of shell. Indeed, even if at the depths of culture used in this study, no influence on the isotopic fractionation coefficient would be expected, depth could have an impact on the "vital effect". The prevailing environmental conditions at the time of the experiment (2004) resulted in temperature homogenization $\left(24^{\circ} \mathrm{C}\right)$, whatever the depth of the lagoon. Consequently, observed variations in the $\delta^{18} \mathrm{O}$ of the shell could only be due to the influence of depth. At equilibrium, $\delta^{18} \mathrm{O}$ can be calculated using the formula of Grossman and $\mathrm{Ku}$ [11] modified by Goodwin et al. [12]:

$$
\mathrm{T}\left({ }^{\circ} \mathrm{C}\right)=20.6-4.34\left(\delta^{18} \mathrm{O}_{\text {aragonite }}-\left(\delta^{18} \mathrm{O}_{\text {water }}-0.2\right)\right)
$$

where $\delta^{18} \mathrm{O}_{\text {aragonite }}$ and $\delta^{18} \mathrm{O}_{\text {shell }}$ are expressed relative to SMOW and PDB, respectively. Here, we assume that the $\delta^{18} \mathrm{O}$ of seawater is $0 \%$. With a temperature of $24{ }^{\circ} \mathrm{C}$, the $\delta^{18} \mathrm{O}$ at equilibrium is $-0.98 \%$. The measured average $\delta^{18} \mathrm{O}$ of the shell ranged between $-1.59 \pm 0.96 \%$ and $-2.38 \pm 0.63 \%$. Therefore, all the values are depleted in ${ }^{18} \mathrm{O}$ relative to the equilibrium value, i.e., the so-called vital effect.

The $\delta^{18} \mathrm{O}$ values in each shell displayed wide variability, between 1.54 and $2.94 \%$ (Figure 5a). Despite this variability, the average $\delta^{18} \mathrm{O}$ for each shell remained similar at the four different depths considered here (Figure $5 \mathrm{~b}$ ). The only difference between the depths was that $\delta^{18} \mathrm{O}$ variability appeared to decrease with depth (Figure 5a). Thus the change in the shape of the nacre tablets had no detectable effect on the $\delta^{18} \mathrm{O}$ of the shell. The fact that depth appears to play no significant role in the $\delta^{18} \mathrm{O}$ of the shell has major implications for paleoceanographic reconstructions.

Figure 5. (a) $\delta^{18} \mathrm{O}$ values (\%o, PDB) measured by SIMS in the inner nacre layer of each shell versus the depth (m) at which the organisms grew. Each error bar takes into account the internal error and the external reproducibility (see text for more details); (b) Average $\delta^{18} \mathrm{O}(\%, \mathrm{PDB})$ for each shell versus depth. The error bars represent the standard deviation $( \pm 1 \sigma)$ of the $\delta^{18} \mathrm{O}$ measurements in each shell ( $\mathrm{n}=9$ to 12 , depending of the sample). No influence of the depth on $\delta^{18} \mathrm{O}$ values was detected.

a)

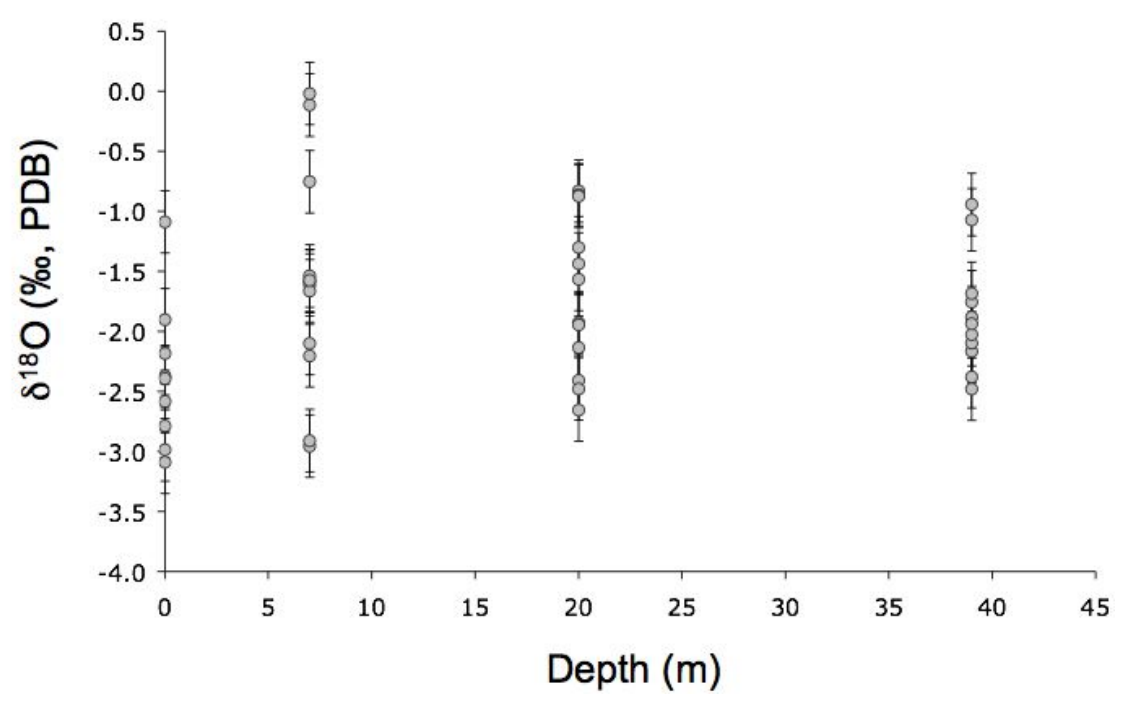


Figure 5. Cont.

b)

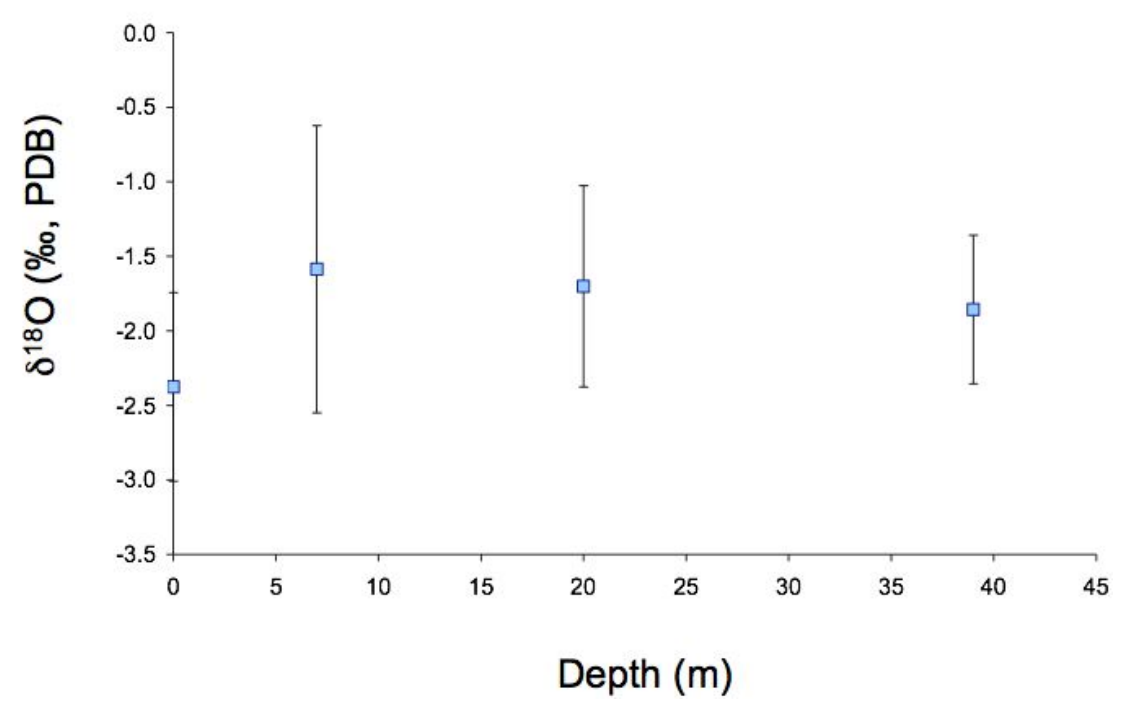

\subsection{Modifications in Thickness and Size}

The thickness and size of the nacre tablets was measured using scanning electron microscopy. Thickness was measured on SEM images of shell fractures not on the presented SEM pictures (pictures not shown). We measured the 10 most recently laid down layers close to the surface of the shell and the 10 oldest layers of the same shell as internal control. The oldest layers had been secreted during the period before the experiment. We then calculated the difference between the two nacre thicknesses as a percentage of the thickness before the experiment began. The thickness of the tablets decreased by between 16 and $30 \%$ on average (Figure 6). In all cases, the change in the environment resulted in a reduction in the thickness of the tablets. The biggest variations were observed at the two extreme depths: close to the surface $(7 \mathrm{~m})$ and far from the surface $(39 \mathrm{~m})$, where conditions are extreme. The second year the reduction in thickness was more important at 7 and $20 \mathrm{~m}$ depth than the first year.

At a depth of $39 \mathrm{~m}$, the shape of the tablets changed from hexagonal to rhomboid, which resulted in a change in size (Figure 7). The size of the tablets increased from 7 to $21 \mu \mathrm{m}^{2}$ with depth. These observations have to be correlated to the growth mechanism of nacre tablets [13]. Tablet formation is the result of a highly dynamic biomineralization process during which organic materials and carbonate precursor phases are delivered to the site of nacre tablet formation from the overlying mantle with a high degree of spatial control. Modifications of the environment like the depth have a direct impact on the shell growth at the scale of tablets.

It has been known for many years that altered gravity, hyper- as well as hypogravity, can influence mineralized structures. Statoliths in Aplysia californica decrease in size under hypergravity [14]. Also, for cichlid fish larvae, hypergravity results in a significantly smaller size of otoliths compared with controls in $1 \mathrm{G}$. No morphological differences with respect to the general shape of the otoliths and the overall pattern of daily incremented ring layers could be found [15]. Marxen et al. [16] studied the influence of microgravity on the embryonic development of the freshwater snail Bomphalaria glabrata and they observed a slower development than under standard conditions. In older embryos a decreased 
mineralization of the shell was detected. In both cases the shell formation proceeded normally. In our study we applied hypergravity and observed a modification of the mineralized structure at the tablet scale.

Figure 6. Percentage reduction in the thickness of nacre layers as a function of depth (m). The error bars represent the standard deviation of the reduction in thickness. We analyzed 5 shells for each depth and measured 10 points in each shell.

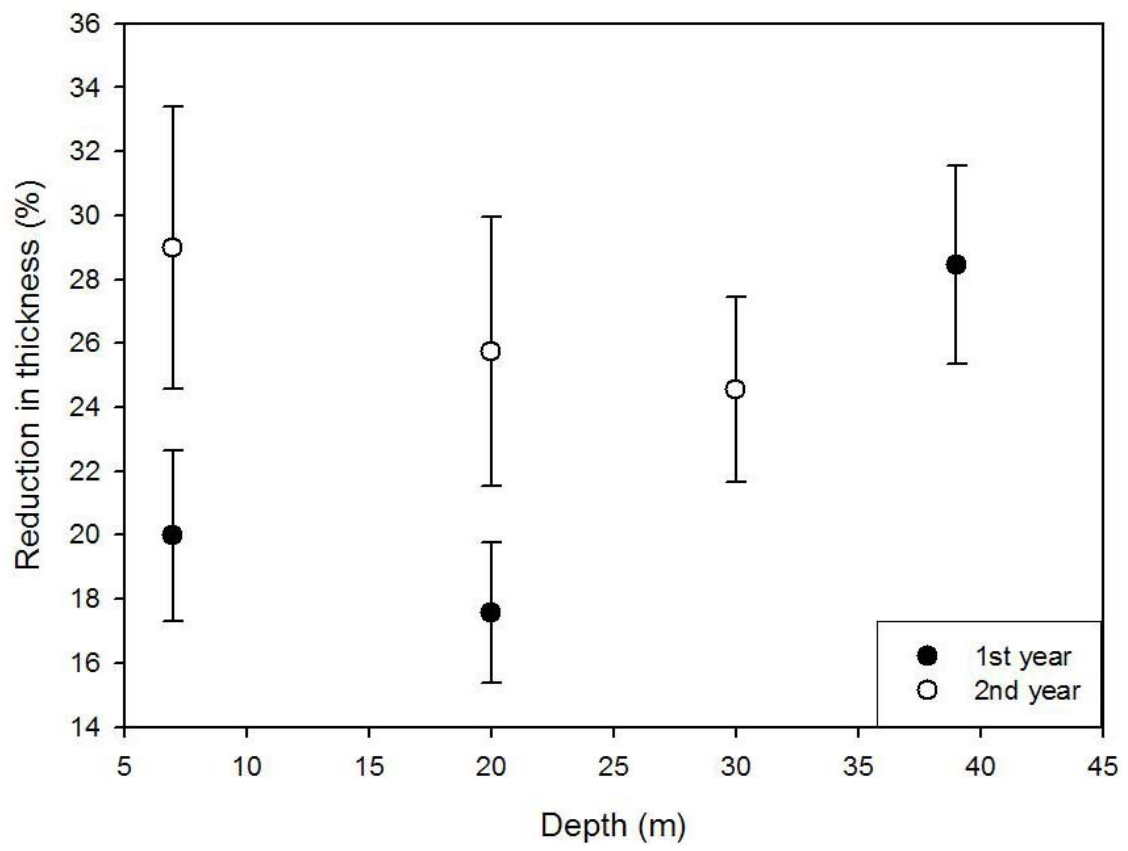

Figure 7. Size of tablets $\left(\mu \mathrm{m}^{2}\right)$ as a function of depth $(\mathrm{m})$. The error bars represent the standard deviation of the tablet size. We analyzed 5 shells for each depth and measured 10 points in each shell.

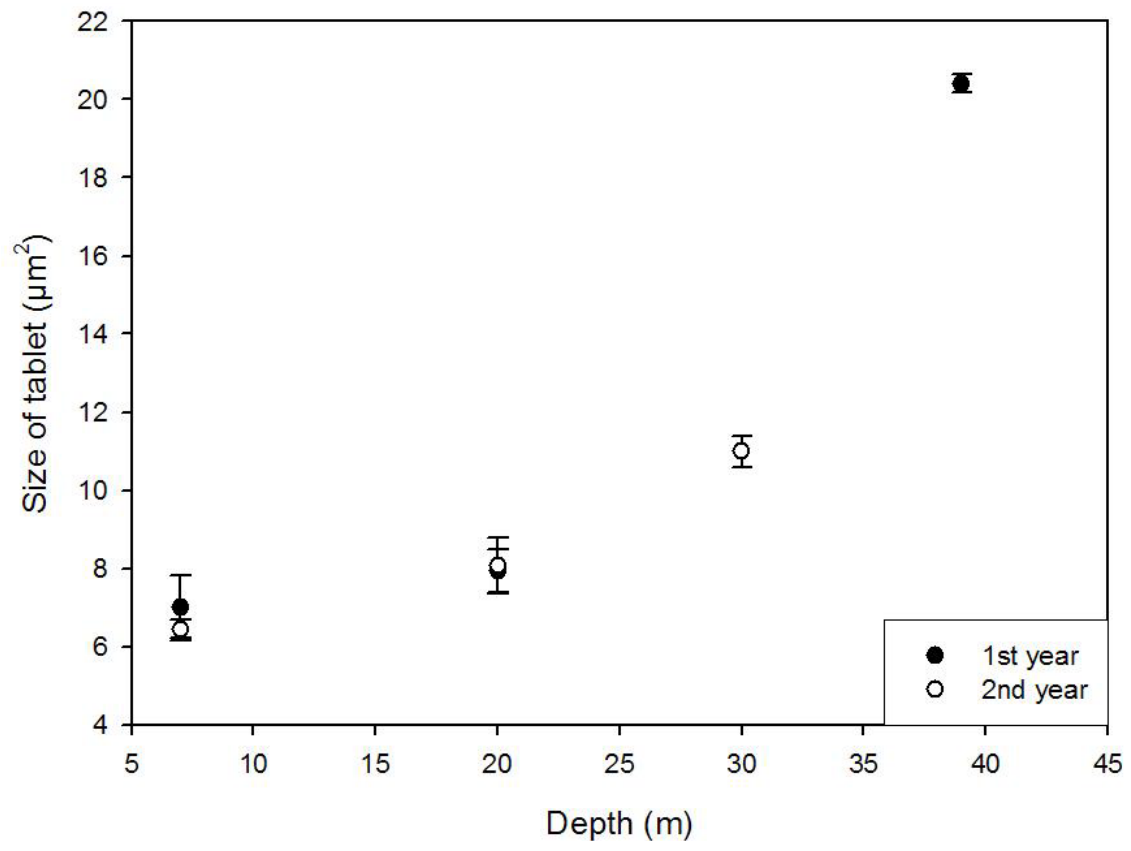




\section{Experimental Section}

\subsection{Experimental Testing}

We studied one-year-old Pinctada margaritifera oysters grown in their natural habitat, at a depth of $12 \mathrm{~m}$, in carefully monitored conditions at Marutea Marine Station, French Polynesia. We then kept the pearl oysters at several different depths at the same station for one week. The oysters were reared on down-lines as they were growing normally. We did not remove them from the line until the end of the experience to avoid any other stress. Only the depth of the line was changed. We used from 10 to 20 pearl oysters for each depth, depending on the numbers of the oysters attached to the line. This experiment was repeated one year later: the first year at depths of 7, 20 and $39 \mathrm{~m}$, and in the second year at depths 7, 20 and $29 \mathrm{~m}$, due to different diving conditions. After one week, the sample oysters were fixed in $70 \%$ ethanol. Five shells were analyzed for each depth.

\subsection{Scanning Electron Microscopy}

The water content was gradually decreased and replaced by increasingly ethanol-rich solutions (3 day baths in $80 \%, 90 \%$ and $100 \%$ ethanol, respectively). After complete dehydration, the shells were opened, allowing the soft tissue of the mantle to be separated from the growing nacre. The shell samples were then air dried. After gold coating, observations were performed at the Electron microscopy service of Life Sciences laboratory, National Museum of Natural History (Paris, France) with a JEOL JSM-840A scanning electron microscope (SEM) operating at $15 \mathrm{kV}$.

\subsection{Oxygen Isotope Measurements}

A piece of each shell grown at a different depth was cut perpendicularly to the growth axis. The samples were mounted in epoxy and polished down to $1-\mu \mathrm{m}$ with diamond paste. Ion probe oxygen isotope analyses of the aragonite part of the shell were performed at CRPG-CNRS (Nancy) using a Caméca ims 1270. The analytical settings were the same as those described in Rollion-Bard et al. [17]. Briefly, a primary beam of $\mathrm{Cs}^{+}$ions with an intensity of about $8 \mathrm{nA}$ was focused on a spot approximately $20 \mu \mathrm{m}$ in diameter. A normal incidence electron flood gun was used to compensate for sample charging during analysis. The measurements were performed in multi-collection mode using two off-axis Faraday cups. Typical intensities were $5 \times 10^{6}$ counts/s (cps) on the ${ }^{18} \mathrm{O}^{-}$peak. The acquisition sequence consisted of 20 cycles of $3 \mathrm{~s}$ duration each.

During analysis, the internal precision was about $\pm 0.1 \%$ and the external reproducibility, based on repeated measurements of an in-house aragonite reference material (Arg, $\delta^{18} \mathrm{O}_{\mathrm{PDB}}=-7.18 \pm 0.11 \%$, [18]) was $\pm 0.25 \%$ o $(1 \sigma)$. The reference material was measured regularly throughout the analytical session.

\section{Conclusions}

We kept pearl oysters for one week at four different depths (7, 20, 30 and $39 \mathrm{~m})$ to influence the shape and thickness of the nacre tablets. Scanning electron microscopy was used to measure the thickness of nacre tablets and to analyze their final shape, which changed from hexagonal to rhomboid at a depth of 39 meters. This change in shape led to a change in the size of the tablets. The thickness of 
the tablets was reduced by between 16 and $30 \%$ on average, this could have an impact on the optical properties of nacre by favoring the luster and iridescent colors. We also measured the oxygen isotopic composition by SIMS. In this study, we demonstrated that depth can modify the size, shape and thickness of nacre tablets, but not the $\delta^{18} \mathrm{O}$ (within the error bars). This environmental modification is important for the biomineralization of the shell of pearl oyster Pinctada margaritifera.

\section{Acknowledgments}

We thank Tahiti Perles for technical and financial support. We thank the divers for enabling us to conduct the experiment at several depths in the lagoon. We thank Gérard Mascarel for his help with the electron microscopy work (Service commun de microscopie électronique des Sciences de la Vie du $M N H N$, Paris, France).

\section{References}

1. Liu, Y.; Shigley, J.E.; Hurwit, K.N. Iridescent colour of a shell mollusc Pinctada margaritifera caused by diffraction. Int. J. Optics 1999, 4 (5), 177-182.

2. Niquil, N.; Pouvreau, S.; Sakka, A.; Legendre, L.; Adessi, L.; Le Borgne, R.; Charpy, L.; Delesalle, B. Trophic web and carrying in a pearl oyster farming lagoon (Takapoto, French Polynesia). Aquat. Living Resour. 2001, 14, 165-174.

3. Pouvreau, S.; Prasil, V. Growth of the blacklip pearl oyster, Pinctada margaritifera, at nine culture sites of French Polynesia: synthesis of several sampling designs conducted between 1994 and 1999. Aquat. Living Resour 2001, 14 (3), 155-163.

4. Wada, K. Nucleation and growth of aragonite crystals in the nacre of some bivalve molluscs. Biomineralization 1972, 6, 141-159.

5. Urey, H.C. Thermodynamic properties of isotopic substances. J. Chem. Soc. 1947, 562-579.

6. Epstein, S.; Buchsbaum, R.; Lowenstam, H.A.; Urey, H.C. Carbonate-water isotopic temperature scale. Bull. Geol. Soc. Amer. 1951, 62, 417-426.

7. Epstein, S.; Buchsbaum, R.; Lowenstam, H.A.; Urey, H.C. Revised carbonate-water isotopic temperature scale. Bull. Geol. Soc. Amer. 1953, 64, 1315-1325.

8. Urey, H.C.; Lowenstam, H.A.; Epstein, S.; McKinney, C.R. Measurement of paleotemperatures and temperatures of the Upper Cretaceous of England, Denmark, and the Southeastern United States. Bull. Geol. Soc. Amer. 1951, 62, 399-416.

9. Rousseau, M.; Lopez, E.; Couté, A.; Mascarel, G.; Smith, D.C.; Naslain, R.; Bourrat, X. Sheet nacre growth mechanism: A Voronoi model. J. Structur. Biol 2005, 149, 149-157.

10. Weiner, S.; Dove, P.M. An overview of biomineralization processes and the problem of the vital effect. In Biomineralization; Dove, P.M., de Yoreo, J.J., Weiner, S., Eds.; The Mineralogical Society of America: Washington, DC, USA, 2003; Volume 54, pp. 1-29.

11. Grossman, E.L.; Ku, T.L. Oxygen and carbon isotope fractionation in biogenic aragonite-Temperature effects. Chem. Geol. 1986, 59, 59-74.

12. Goodwin, D.H.; Flessa, K.W.; Schöne, B.R.; Dettman, D.L. Cross-calibration of daily growth increments, stable isotope variation, and temperature in the Gulf of California bivalve mollusk Chione cortezi: Implication for paleoenvironmental analysis. Palaios 2001, 16, 387-398. 
13. Rousseau, M.; Meibom, A.; Gèze, M.; Bourrat, X.; Angellier, M.; Lopez, E. Dynamics of sheet nacre formation in bivalves. J. Structur. Biol. 2009, 165, 190-195.

14. Pedrozo, H.A.; Wiederhold, M.L. Effects of hypergravity on statocyst development in embryonic Aplysia californica. Hear. Res. 1994, 79, 137-146.

15. Anken, R.H.; Kappel, T.; Rahmann, H. Morphometry of fish inner ear otoliths after development at 3g hypergravity. Acta Oto-laryngol. 1998, 118, 534-539.

16. Marxen, J.; Reelsen, O.; Becker, W. Embryonic development of the freshwater snail Biomphalaria glabrata under $\mu \mathrm{g}$ conditions (STS-89 mission). J. Gravit. Physio. 2001, 8, 29-36.

17. Rollion-Bard, C.; Blamart, D.; Cuif J.-P.; Dauphin, Y. In situ measurements of oxygen isotopic composition in deep-sea coral, Lophelia pertusa: Re-examination of the current geochemical models of biomineralization. Geochim. Cosmochim. Acta 2010, 74, 1338-1349.

18. Rollion-Bard, C.; Mangin, M.; Champenois, M. Development and application of oxygen and carbon isotopic measurements of biogenic carbonates by ion microprobe. Geostand. Geoanal. Res. 2007, 31, 39-50.

(C) 2012 by the authors; licensee MDPI, Basel, Switzerland. This article is an open access article distributed under the terms and conditions of the Creative Commons Attribution license (http://creativecommons.org/licenses/by/3.0/). 